\title{
An experimental hut evaluation of Olyset Plus, a long-lasting insecticidal net treated with a mixture of permethrin and piperonyl butoxide, against Anopheles fluviatilis in Odisha State, India
}

\author{
Kasinathan Gunasekaran ${ }^{1 *}$, Sudhansu Sekhar Sahu ${ }^{1 *}$, Tharmalingam Vijayakumar ${ }^{1}$, \\ Swaminathan Subramanian ${ }^{1}$, Rajpal Singh Yadav², Olivier Pigeon ${ }^{3}$ and Purushothaman Jambulingam
}

\begin{abstract}
Background: Fast development of pyrethroid resistance in malaria vectors prompted the development of new vector control tools including combination of insecticides with different modes of action as part of resistance management strategies. Olyset Plus ${ }^{\circledR}$ is a new long-lasting insecticidal net, in which, permethrin and a synergist, piperonyl butoxide (PBO), are incorporated into filaments. Mixture nets such as this may have application against resistant mosquitoes, particularly those whose resistance is based on oxidative metabolism. There may also be enhanced activity against susceptible mosquitoes since mixed function oxidases are involved in a many metabolic activities including activation to form bioactive compounds.

Methods: Bio-efficacy of Olyset Plus was evaluated against susceptible malaria vector, Anopheles fluviatilis in experimental huts. Deterrence, blood feeding inhibition, induced exophily and killing effect were measured to assess the bio-efficacy. The results were compared with Olyset $\mathrm{Net}^{\circledR}$, a polyethylene permethrin-incorporated LLIN and a conventionally treated polyester net (with permethrin) washed to just before exhaustion.

Results: Results showed significant reduction in entry (treatment: $0.4-0.8$; control: 4.2 per trap-night) and increase in exit (56.3-82.9\% and $44.2 \%$ ) rates of Anopheles fluviatilis in the treatment arms compared to control $(P<0.05)$. While blood feeding rates declined in treatment arms (18.8-30.6\%), it increased in control (77.6\%) $(P<0.05)$. This was further evident from the blood-feeding inhibition rates in treatment arms (60.6-90.6\%). Total mortality was significantly higher in all treatment arms (96.3-100 \%) compared to control arm (2\%) $(P<0.05)$. Chemical analysis for active ingredient (Al) showed retention of 75 and $88 \%$ in Olyset plus and Olyset net respectively after 20 washes. Performance of Olyset Plus washed 20 times was equal to the CTN and Olyset Net against the susceptible malaria vector An. fluviatilis, fulfilling the WHO efficacy criteria of Phase II evaluation for LLIN. However, the benefit of incorporating PBO and permethrin together in a long-lasting treatment could not be demonstrated in the current study as the target vector species was fully susceptible to pyrethroids.
\end{abstract}

Conclusion: Olyset Plus, with its intrinsic bio-efficacy could be an effective vector control tool to prevent transmission of malaria by susceptible vectors like An. fluviatilis. However, the results of the current study need to be further supported by testing the net at village level (Phase III) for community acceptability. Before taking the net to village level, it needs to be verified whether the net is better than pyrethroid nets in terms of bio-efficacy against resistant An. culicifacies, another malaria vector that has developed resistance to synthetic pyrethroids in India.

\footnotetext{
*Correspondence: k_guna@yahoo.com; sssahu1961@gmail.com

${ }^{1}$ Vector Control Research Centre (ICMR), Medical Complex, Indira Nagar,

Puducherry 605 006, India

Full list of author information is available at the end of the article
} 
Keywords: Anopheles fluviatilis, Experimental-hut, Olyset Plus, Olyset Net, Odisha, India

\section{Background}

Plasmodium falciparum is the predominant human malaria parasite in India and of the total cases reported in 2015 , its proportion was $67.2 \%(n=1.12$ million), followed by Plasmodium vivax [1]. Effective and large scale implementation of conventional tools [indoor residual spraying, insecticide-treated nets (ITNs)/long-lasting insecticidal nets (LLINs), larvicides] have distinctly brought down the malaria cases from 2.08 million to 1.31 million during 2001-2011 [2]. One of the major strategies being pursued for malaria control by the National Vector Borne Disease Control Programme (NVBDCP) is the distribution of LLINs in endemic areas since 2009 [1] and so far around 21 million nets have been distributed in the country [3].

LLIN is the most technologically advanced form of insecticide-treated net currently used for malaria control $[4,5]$. The LLINs, which retain insecticidal efficacy without retreatment for 3-5 years, represent an important innovation that is being scaled up globally for malaria prevention [68]. These nets are made up of synthetic fibers (polyester and polyethylene) that have been compounded with an insecticide. The net kills or repels mosquitoes and it provides a physical barrier to them. Studies have demonstrated that presence of a LLIN also dejects mosquitoes from remaining in the surroundings [9]. Among the LLINs undergone trials so far, DuraNet ${ }^{\circledR}$, Interceptor ${ }^{\circledR}$, MAGNet $^{\mathrm{TM}}$, Olyset Net ${ }^{\circledR}$, PermaNet $^{\circledR}$ 2.0, Royal Sentry ${ }^{\circledR}$ and Yorkool ${ }^{\mathrm{TM}}$ received full recommendation (a full recommendation implies that the net has undergone long-term testing under operational conditions) of World Health Organization Pesticide Evaluation Scheme (WHOPES) while DawaPlus ${ }^{\circledR} 2.0$, LifeNet $^{\circledR}$, Olyset Plus ${ }^{\circledR}$ and PermaNet ${ }^{\circledR} 3.0$ have been awarded with interim recommendation (an interim recommendation is granted after satisfactory completion of laboratory and small-scale field-testing of the given net) [10-12]. Two brands of LLINs viz., Olyset Net and PermaNet are already in use in some countries, including India.

Efficacy of LLINs so far relies exclusively on a single class of insecticide, synthetic pyrethroids, to which there are many reports of resistance in vector populations adopting various mechanisms [13-15]. In a multi-centre study in Western and Central Africa, field efficacy of a deltamethrin + piperonyl butoxide treated mosaic net (PermaNet ${ }^{\circledR} 3.0$ ) was tested in experimental huts against pyrethroid resistant malaria vectors, Anopheles gambiae and Anopheles arabiensis and compared with PermaNet 2.0., a deltamethrin-coated LLIN. PermaNet 3.0 caused higher efficacy against the resistant malaria vectors than PermaNet ${ }^{\circledR}$ 2.0. However, in areas of strong resistance like the Vallée du Kou (Southern Burkina
Faso), a large number of exposed mosquitoes survived after the exposure to both LLINs [16]. In another study in Benin, blood feeding of pyrethroid resistant An. gambiae was not inhibited by insecticide-treated nets, whereas inhibition was $96 \%$ among susceptible mosquitoes. Also, the mortality rate of An. gambiae in resistant area was only $30 \%$ against $98 \%$ mortality in susceptible area [17]. Further, the household trials in northern and southern Benin showed insecticide treated nets provided little or no protection against pyrethroid resistant An. gambiae [18]. Due to fast development of pyrethroid resistance in malaria vectors worldwide, industries started manufacturing new vector control tools including insecticide mixtures containing at least two active ingredients with different modes of action as part of resistance management. Development of a net incorporating a pyrethroid with a synergist is promising against pyrethroid resistant malaria vectors. Synergists are chemicals that lack pesticidal effects of their own but enhance the pesticidal properties of other chemicals. One such newer vector control tool is Olyset Plus, a durable LLIN made of mono-filament polyethylene yarn, containing $2 \%(\mathrm{w} / \mathrm{w})$ technical permethrin (40:60 cis:trans isomer ratio) as active ingredient (AI), corresponding to $20 \mathrm{~g} \mathrm{AI} / \mathrm{kg}$ (about $800 \mathrm{mg} \mathrm{AI} / \mathrm{m}^{2}$ ), and $1 \%(\mathrm{w} / \mathrm{w})$ piperonyl butoxide (PBO), as synergist, corresponding to $10 \mathrm{~g} \mathrm{PBO} / \mathrm{kg}$ (about $400 \mathrm{mg} \mathrm{PBO} / \mathrm{m}^{2}$ ). Permethrin and the synergist are incorporated into filaments and the active ingredients slowly diffuses over the lifetime of the net to maintain a constant surface concentration. Mixture nets such as this may have application against resistant mosquitoes, particularly those whose resistance is based on oxidative metabolism [9]. There may also be enhanced activity against susceptible mosquitoes since mixed function oxidases are involved in many metabolic activities including activation of many substances to form their bio-active compounds [9]. Olyset Plus was made available by the WHOPES for Phase II evaluation (in Phase II, efficacy of washed and unwashed LLINs is evaluated in experimental huts against wild, free flying anopheline mosquitoes) in India. The current paper presents the results of the evaluation of efficacy of Olyset Plus LLIN carried out in experimental huts during 2011-2013 against a wild, free flying susceptible population of Anopheles fluviatilis sensu lato, in terms of mortality, deterrence, blood-feeding inhibition and induced exophily, in Odisha state, East-Central India following the WHO guidelines [19].

\section{Methods \\ Study area}

Kandhaguda village of Malkangiri District in Odisha State (East-Central India) was the field site. The terrain of 
the village is hilly and forested with a stream crisscrossing (altitude 150-200 m MSL). Climate is characterized by summer (March-June), rainy (July-October) and cold seasons (November-February). The village has been endemic for $P$. falciparum malaria with two transmission peaks, July-August and October-November; An. fluviatilis is the major malaria vector [5]. The village is under Pandripani Community Health Centre that recorded an annual parasite incidence (API) of $13.2-33.8$ per 1000 population during 2013-2015. Yearly, two rounds of indoor residual spraying with DDT have been carried out in the district (Malkangiri); in addition, LLINs (PermaNet 2.0) were distributed during 2012-2013. The six experimental huts constructed in the village were used for the Phase II evaluation of Olyset Plus.

\section{Experimental hut}

The experimental hut is specially designed for recording the entering and exiting behaviour of mosquitoes and for measuring response to insecticides/treated nets including mortality. The hut consists of a single room with four windows; size of each window was $0.45 \times 0.45 \mathrm{~m}$, grilled with wooden planks fixed horizontally in tilted position one above the other leaving a gap of $1 \mathrm{~cm}$ between two planks through which mosquitoes could enter into the hut but could not exit. There are two windows on the front door side and one on each of the sides and a screened (using nylon mesh) verandah at the backside. The dimensions of the huts resemble to those of the village huts (length $3 \mathrm{~m}$, width $3 \mathrm{~m}$ and height $2.5 \mathrm{~m}$ ) having brick walls with cement plastering and thatched roof, above which there are tin-sheeted roofing for protecting the thatched roof. There is no space between the thatched ceiling and tin-roofs. The huts are constructed one foot above the ground level on a platform made up of brick and cement. The platform has a water-filled moat ( $6^{\prime}$ depth $\times 6^{\prime}$ breadth) all around to deter entry of scavenging ants. The moat is made at two feet away from the hut walls, except on the back side of the hut where it is at $1.5 \mathrm{ft}$ away from the base of the verandah trap. At the centre of the hut, the roof is at a height of $2.5 \mathrm{~m}$ and near the wall the height is $2 \mathrm{~m}$; this difference in height is to maintain a slope of the roof. The eave on the backside (facing towards east) has a gap of 1-2 $\mathrm{cm}$ and through this gap mosquitoes could exit, but those mosquitoes will be collected in the verandah trap. There is one wooden door of $0.75 \mathrm{~m} \times 1.5 \mathrm{~m}$ facing towards west (Figs. 1, 2).

\section{Experiment arms}

The test nets (size $220 \mathrm{~cm}$ long, $170 \mathrm{~cm}$ wide, $150 \mathrm{~cm}$ high) were received from the WHOPES. The evaluation was single blinded one as the nets were coded by a person who did not involve directly in field evaluation and the codes were not communicated to the field staff. Further,

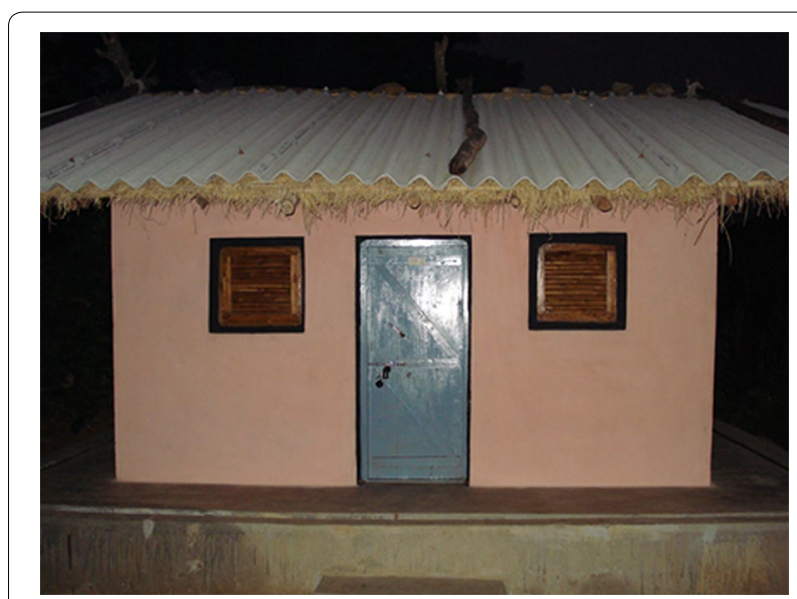

Fig. 1 Front view of the experimental hut used for the Phase II evaluation

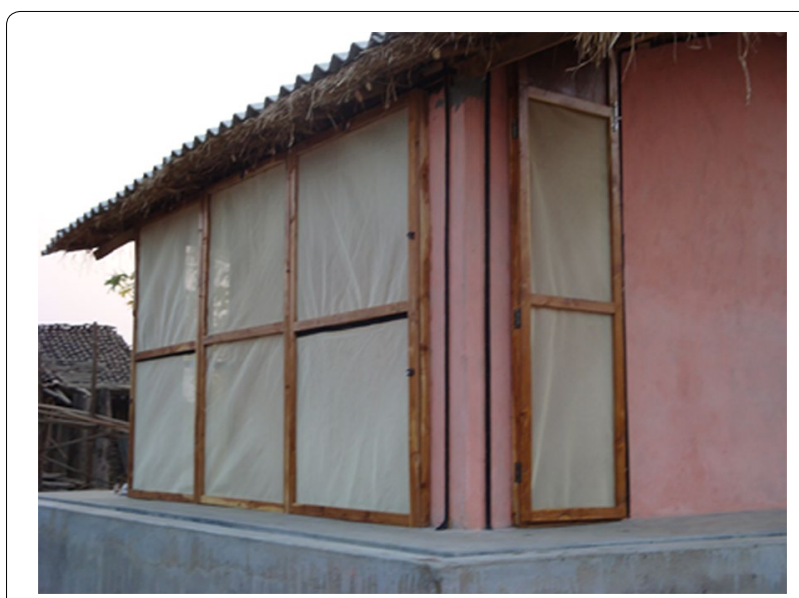

Fig. 2 Rear view of the experimental hut showing verandah (exit) trap

washing of nets and bioassay before and after washing were done at Vector Control Research Centre, Puducherry thereby ensuring the field staff who conducted the evaluation in experimental huts were not knowing the details of the nets. The evaluation included six comparison arms viz., unwashed Olyset Plus, Olyset Plus washed 20 times, unwashed Olyset Net, Olyset Net washed 20 times (positive control), polyester net conventionally treated with permethrin at $500 \mathrm{mg} / \mathrm{m}^{2}$ washed to just before exhaustion (reference net) and polyester untreated net (negative control). The nets were coded indicating the six arms and the six replicate nets and the two additional nets in each arm. Six replicate nets were used per each arm and each net was tested one night per week. The two additional nets were used for cone bioassay and chemical analysis prior to any wash and after 20 washes or washed to just before exhaustion. 


\section{Washing, cone-bioassays and chemical analysis}

Olyset Plus and Olyset Net were washed 20 times and the conventionally treated nets (CTN) were washed to just before exhaustion (seven nets in each Arm) [19]. The point of exhaustion was determined by washing the net and performing cone bioassay after each wash. The last wash for which the net still caused $>80 \%$ mortality or $>95 \% \mathrm{KD}$ was considered to be the number of washes required before exhaustion. Considering a regeneration time of 2 days for Olyset Plus and 7 days for Olyset Net, the wash interval was kept respectively, as 2 and 7 days.

Bioassays were performed on the nets using the WHOprescribed cones and the laboratory reared, blood-fed, susceptible Anopheles stephensi before any wash (to confirm the efficacy of the insecticide treatment of the nets) and after 20 washes (to assess the wash resistance of the treated nets) or washes until just before exhaustion at the VCRC laboratory, Puducherry. For bioassays, the target vector species, An. fluviatilis, could not be used as rearing facility of this species was not available at the VCRC laboratory, where net washing was done. On each net, $5 \times 2$ cone tests were performed (one cone on each section of the net: roof and 4 sides, repeated 2nd time) exposing five mosquitoes per cone test. Exposure to net lasted for $3 \mathrm{~min}$ after which mosquitoes were held for $24 \mathrm{~h}$ with access to sugar solution. Knock down was measured $60 \mathrm{~min}$ after exposure time and mortality after $24 \mathrm{~h}$. Results were pooled for the 50 mosquitoes tested per net.

Prior to any wash, 5 pieces of $30 \times 30 \mathrm{~cm}$ nettings were taken from one of the two additional nets of each of the six arms. Similarly, net samples were obtained after 20 washes or after washes until just before exhaustion (from the second additional net). Also, at the end of the experimental hut evaluation, one used-net from each arm was sampled. The samples were analyzed for insecticide content.

The nets, after washings and bioassays, were shifted to the field site for evaluation in experimental huts. Before hut evaluation, cone-bioassay using wild caught susceptible blood-fed An. fluviatilis was performed on one randomly selected net out of the six replicate nets from each arm. Six holes, two each on long sides and one each on front and hind ends were made (size of each hole was $4 \mathrm{~cm} \times 4 \mathrm{~cm}$ ) on all replicate nets of the six arms to simulate the conditions of a torn net and to put emphasis on testing whether the insecticide treatment, rather than the net, effectively prevents mosquito biting of sleepers. At the end of the hut evaluation, cone-bioassay, exposing field collected blood-fed An. fluviatilis, was conducted on one randomly selected net of each arm used in the huts.

\section{Selection of volunteers}

Twelve village volunteers, two per hut (they would either be couples or two family members together, who would be provided with equal number of beds), were selected to sleep in the experimental huts under the mosquito net provided to them (two volunteers under one double size net,) from dusk to dawn with a small break for dinner. The volunteers (sleepers) were apprised that they should be available for the entire period of the hut evaluation and should maintain the same behavioural patterns (such as hut entering time, clothing, using bed materials, nonsmoking, not making fire, sleeping under mosquito net, etc.) throughout, as these could constitute a significant source of variation that must be controlled for. Informed consent was obtained from all the volunteers and each one was remunerated. To involve human volunteers in the study, clearance was obtained from the Institute's Human Ethics Committee.

\section{Hut acclimatization and suitability}

For acclimatization, one adult volunteer slept overnight inside the experimental huts under an ordinary mosquito net for 1 month. Subsequently, hut suitability was ascertained by comparing the density of An. fluviatilis resting in the experiment huts with that in the village huts and by assessing recovery and scavenging rates. For recovery, known number of female anophelines were released into the huts in the evening and recaptured in the next day morning. To verify the presence of scavengers inside the huts, 10 dead Anopheles mosquitoes were placed on the floor (in four corners) of the huts in the evening, twice in a week. In the following morning, the places were checked for presence of dead mosquitoes and the available ones were picked up and counted.

\section{Evaluation in experimental huts}

The nets of the six arms were evaluated in the six experimental huts. Each arm had six replicate nets and each net was tested one night per week. Thus, the six replicate nets of each arm were tested in one experimental hut in 1 week during six successive nights. Likewise, the replicate nets of the other five arms were evaluated in the other five experimental huts. Sleepers were organized in six teams, each with two persons. The teams formed in the beginning were not changed.

\section{Rotation of arms and volunteers}

Using the Latin Square Rotation Scheme, the nets and the sleepers were rotated between the experimental huts. In practice, sleepers were rotated daily whereas arms weekly. Six replicate nets were used per arm and each net was tested one night during a week. In the morning, the nets were removed from the huts and stored in separate 
labelled bags. At the end of every week, mosquito nets together with bed materials and the white cloth spread on the floor of the room and verandah were removed from the huts. The huts were then cleaned and ventilated to remove any contamination from the nets previously used. The foot-mat and the beds (labelled arm-wise) were rotated by treatment with the arms since they came in close contact with the treated net.

\section{Mosquito collection}

In the previous evening to each day of mosquito collection, prior to the volunteers stepped into the hut for sleeping, clean white cloths were spread on the floor of the hut (room and verandah), and the gutter all around the hut was filled with water.

The sleepers got into the experimental huts at $1900 \mathrm{~h}$ and remained inside until $0530 \mathrm{~h}$; during that period they slept under the mosquito net provided to them. In the morning, resting and dead mosquitoes were collected separately from veranda, room (walls, roof, floor), and inside bed-net using a mouth aspirator and kept separately by hut and by collection place. The mosquitoes were identified morphologically and graded according to their abdominal condition (blood fed/unfed/semi-gravid + gravid). Alive mosquitoes were placed in wax coated paper cups (each $250 \mathrm{ml}$ capacity) with access to sugar solution for $24 \mathrm{~h}$ and after which mortality was recorded. Mosquito collections were continued up to 12 weeks post-distribution of nets. Side effects perceived, if any, by the volunteers during or after sleeping under the nets in the experimental huts were recorded through interviews.

\section{Chemical analysis for active ingredient content in net samples}

The net samples obtained prior to any wash, after 20 washes and at the end of hut evaluation were analysed for active ingredient content at the Walloon Agricultural Research Centre, CRA-W, Gembloux, Belgium. The 5 pieces of $25 \mathrm{~cm} \times 25 \mathrm{~cm}$ (one from roof and four from four side panels) of each net sample were cut with scissors in 4 quarters according to the diagonal. One quarter was taken from each net piece and the 5 quarters were pooled in order to form a sub-sample representative of the net sample. The sub-sample was cut with scissors into small pieces of 5-10 $\mathrm{mm}^{2}$, homogenized and an analytical portion was weighed for determination of permethrin and/or PBO. A piece of $10 \mathrm{~cm} \times 10 \mathrm{~cm}$ was also cut from the top piece in order to determine the density.

\section{Data analysis}

The nets were decoded after completion of the hut trial. The data were analysed to determine the effect of the six arms in terms of deterrence (the number of mosquitoes caught in the hut with a treated net, as a percentage of the number in the hut with untreated net), induced exophily (increasing of exit rate [exit rate is the number of mosquitoes caught in the veranda trap, as a percentage of the total number caught in the hut including under bed-net and veranda] in the treated arm compared with the untreated arm), blood-feeding inhibition (the proportional reduction of blood feeding in huts with treated nets relative to huts with untreated nets), and total mortality (the number of mosquitoes found dead either at dawn [immediate mortality] or $24 \mathrm{~h}$ later [delayed mortality] as a percentage of the total numbers caught in the hut). The number of An. fluviatilis caught in each hut was tabulated by day and checked for variance and mean. Since, variance was greater than mean, the numbers caught (hut entry) were statistically analyzed using negative binomial regression. The exit, blood feeding and mortality rates were compared between the untreated (negative control) and the treated arms using logistic regression analysis (Stata software, Version 10). Since the total mortality was $100 \%$ with the unwashed Olyset Net, conventionally treated polyester net and unwashed Olyset Plus, the logistic regression analysis was restricted to untreated polyester net, Olyset Net washed 20 times and Olyset Plus washed 20 times and the results were compared among these arms.

\section{Results}

\section{Hut suitability}

The resting density of An. fluviatilis in the experimental huts was about 2.5 times higher than that in the tribal huts. The recovery rate of An. fluviatilis was $>80 \%$ (84$91.7 \%)$ on all the five occasions tested in the six huts. The scavenging rate was almost nil in most of the times tested, except on a few occasions in the beginning, when the scavenging rate was around $3 \%$. Although, the huts were made ant-proof by filling the gutter around the hut with water, house crickets, Gryllodes sigillatus were found scavenging on dead mosquitoes; this problem was overcome by cleaning the rooms, verandah and surroundings of the huts every day.

\section{Species composition}

From the 72 nights of collections per experimental hut, i.e. six nights in a week for 12 weeks, the total mosquito catch was 965 . About $53 \%$ of them were An. fluviatilis. Anopheles culicifacies, the secondary malaria vector, formed only $1.9 \% ; 14.9 \%$ was other anophelines and $29.8 \%$ culicines. Since, An. culicifacies was collected in very low numbers; further analysis was done only for An. fluviatilis. Results of the entomological collections and statistical analysis are summarized, respectively in Tables 1 and 2. 
Table 1 Comparison of performance of the six experimental arms against wild Anopheles fluviatilis in experimental huts

\begin{tabular}{|c|c|c|c|c|c|c|}
\hline Arms & $\begin{array}{l}\text { Untreated } \\
\text { polyester net }\end{array}$ & $\begin{array}{l}\text { Unwashed } \\
\text { Olyset Net }\end{array}$ & $\begin{array}{l}\text { Conventionally } \\
\text { treated } \\
\text { polyester net }\end{array}$ & $\begin{array}{l}\text { Olyset Net } \\
\text { washed } 20 \text { times }\end{array}$ & $\begin{array}{l}\text { Olyset Plus } \\
\text { washed } \\
20 \text { times }\end{array}$ & $\begin{array}{l}\text { Unwashed } \\
\text { Olyset Plus }\end{array}$ \\
\hline Number of collections & 72 & 72 & 72 & 72 & 72 & 72 \\
\hline $\begin{array}{l}\text { Number of females entered/ } \\
\text { caught }\end{array}$ & 303 & 49 & 41 & 54 & 36 & 32 \\
\hline $\begin{array}{l}\text { Number of females caught } \\
\text { per night }\end{array}$ & $4.2^{\mathrm{a}}$ & $0.7^{b}$ & $0.6^{b}$ & $0.8^{\mathrm{b}}$ & $0.5^{b}$ & $0.4^{\mathrm{b}}$ \\
\hline Deterrence in \% (95 \% Cl) & - & $83.8^{\mathrm{a}}(79.7,88.0)$ & $86.5^{\mathrm{a}}(82.6,90.3)$ & $82.2^{\mathrm{a}}(77.9,86.5)$ & $88.1^{\mathrm{a}}(84.5,91.8)$ & $89.4^{\mathrm{a}}(86.0,92.9)$ \\
\hline Exit rate in \% (95 \% Cl) & $44.2^{\mathrm{a}}(38.6,49.8)$ & $69.4^{\mathrm{b}}(56.5,82.3)$ & $82.9^{b}(71.4,94.4)$ & $70.4^{b}(58.2,82.5)$ & $77.8^{\mathrm{b}}(64.2,91.4)$ & $56.3^{\mathrm{ab}}(39.1,73.4)$ \\
\hline Blood feeding in \% (95 \% Cl) & $77.6^{\mathrm{a}}(72.9,82.3)$ & $26.5^{b}(14.2,38.9)$ & $7.3^{b}(1.5,19.9)^{*}$ & $29.6^{\mathrm{b}}(17.5,41.8)$ & $30.6^{\mathrm{b}}(15.5,45.6)$ & $18.8^{\mathrm{b}}(5.2,32.3)$ \\
\hline $\begin{array}{l}\text { Blood feeding inhibition in \% } \\
\text { (95\% Cl) }\end{array}$ & - & $65.9^{\mathrm{a}}(45.3,78.6)$ & $90.6^{\mathrm{a}}(71.9,96.8)$ & $61.9^{\mathrm{a}}(42.1,74.8)$ & $60.6^{\mathrm{a}}(35.3,76.0)$ & $75.8^{\mathrm{a}}(50.1,88.3)$ \\
\hline Total mortality in \% (95 \% Cl) & $2.0^{\mathrm{a}}(0.4,3.5)$ & $100.0^{b}(100,100)$ & $100.0^{b}(100,100)$ & $96.3^{b}(87.2,99.6)^{*}$ & $97.2^{\mathrm{b}}(85.5,99.9)^{*}$ & $100.0^{b}(100,100)$ \\
\hline
\end{tabular}

Numbers in the same row sharing a letter superscript do not differ significantly $(P>0.05)$

Total mortality $=$ Immediate mortality + Delayed mortality

Confidential intervals (Cls) for percentages are based on normal approximation to binomial distribution, except the Cls marked with asterisk that are based on exact binomial distribution

Table 2 Results of statistical analysis of the performance of the six experimental arms against wild An. fluviatilis in experimental huts

\begin{tabular}{|c|c|c|c|c|c|c|}
\hline Variables & $\begin{array}{l}\text { Untreated } \\
\text { polyester net }^{a}\end{array}$ & $\begin{array}{l}\text { Unwashed Olyset } \\
\text { Net }\end{array}$ & $\begin{array}{l}\text { Conventionally } \\
\text { treated polyester } \\
\text { net }\end{array}$ & $\begin{array}{l}\text { Olyset Net washed } 20 \\
\text { times }\end{array}$ & $\begin{array}{l}\text { Olyset Plus } \\
\text { washed } 20 \text { times }\end{array}$ & $\begin{array}{l}\text { Unwashed } \\
\text { Olyset Plus }\end{array}$ \\
\hline \multicolumn{7}{|l|}{ Entry (deterrence) } \\
\hline $\operatorname{IRR}(95 \% \mathrm{CI})$ & 1.0 & $0.16(0.10-0.26)$ & $0.14(0.08-0.22)$ & $0.18(0.11-0.28)$ & $0.12(0.07-0.20)$ & $0.11(0.06-0.18)$ \\
\hline Z & & -7.61 & -8.08 & -7.33 & -8.38 & -8.61 \\
\hline $\mathrm{P}$ & & $<0.001$ & $<0.001$ & $<0.001$ & $<0.001$ & $<0.001$ \\
\hline \multicolumn{7}{|c|}{ Exit (induced exophily) } \\
\hline Odds ratio $(95 \%$ Cl) & 1.0 & $2.86(1.50-5.47)$ & $6.13(2.63-14.25)$ & $2.99(1.60-5.61)$ & $4.41(1.95-10.00)$ & $1.62(0.78-3.38)$ \\
\hline Wald statistics & & 10.08 & 17.70 & 11.78 & 12.66 & 1.67 \\
\hline $\mathrm{P}$ & & 0.001 & $<0.001$ & 0.001 & $<0.001$ & 0.197 \\
\hline \multicolumn{7}{|c|}{ Blood feeding (inhibition) } \\
\hline Odds ratio $(95 \%$ Cl) & 1.0 & $0.10(0.05-0.21)$ & $0.02(0.01-0.08)$ & $0.12(0.06-0.23)$ & $0.13(0.06-0.27)$ & $0.07(0.03-0.17)$ \\
\hline Wald statistics & & 41.25 & 37.72 & 41.12 & 28.34 & 32.69 \\
\hline $\mathrm{P}$ & & $<0.001$ & $<0.001$ & $<0.001$ & $<0.001$ & $<0.001$ \\
\hline \multicolumn{7}{|l|}{ Total mortality (killing) } \\
\hline Odds ratio (95 \% Cl) & 1.0 & $b$ & $b$ & $1287.0(252.9-6550.3)$ & $\begin{array}{l}1732.5(202.7- \\
14810.7)\end{array}$ & $\mathrm{b}$ \\
\hline Wald statistics & & & & 74.38 & 46.40 & \\
\hline $\mathrm{P}$ & & & & $<0.001$ & $<0.001$ & \\
\hline
\end{tabular}

a Reference category for all variables, IRR incidence rate ratio

b As the mortality was $100 \%$ in these arms, they were excluded from the logistic regression analysis

\section{Entry}

In the huts with the untreated control net, mosquito entry was zero on 10 occasions (out of 72 nights of collections), whereas with the five treatments, zero catch was recorded on 47, 44, 46, 51 and 54 occasions, respectively, indicating a marked deterrent effect of permethrin. While, 303 An. fluviatilis entered the control arm (with untreated net), the number entered the five treatment arms together was only 212 . The deterrent effect of permethrin was further evidenced from a higher catch of An. fluviatilis under untreated net (57 of 303) compared to a very few catch under treated nets $(1 / 49,0 / 41,0 / 54,2 / 36$ and $1 / 32$, respectively) in spite of six holes made in all treated and untreated nets to simulate the conditions of a torn net. 
The outcome of the negative binomial regression analysis (performed with the number caught as dependent variable and the six experiment arms as independent variable) revealed that the hut entry of An. fluviatilis was over-dispersed (non-random) ( $\alpha$ that measures over-dispersion $=1.21$ (95\% CI: 0.87-1.67), $\chi^{2}=190.35, \mathrm{df}=5$, $\mathrm{p}<0.0001)$ and justified the analysis. The entry was significantly lower with all treatments compared to the control $(\mathrm{p}<0.05)$. Among the five treated arms, the lowest entry was with unwashed Olyset Plus followed by Olyset Plus washed 20 times (Table 1). However, the $95 \%$ CI for the incidence rate ratio (IRR) indicated no significant difference between the treatment arms (Table 2).

\section{Exit}

The exophily from the control hut (natural exophily) was $44.2 \%$ and from the huts with treated nets it ranged from 56.3 to $82.9 \%$. The number exited on each day in each arm during the evaluation period was subjected to logistic regression analysis by taking mosquito exit as dependent variable, the six arms as categorical covariates and the untreated net as reference category. All treatments induced significantly higher exophily than the untreated net $(\mathrm{p}<0.05)$, except the unwashed Olyset Plus ( $\mathrm{p}>0.05$ ) (Table 1). However, there was no significant difference between the five treatments, as shown by $95 \%$ CI for the odds ratio (Table 2).

\section{Blood feeding}

Overall, the blood feeding rate differed significantly between the six arms (Wald statistics $=125.7, \mathrm{p}<0.001$ ). Though, none of the treatments inhibited blood-feeding completely, blood feeding inhibition (BFI) rates were significantly higher with all treatments compared to the control ( $\mathrm{p}<0.001)$ (Table 1). Among the treatments, BFI was the highest with the conventionally treated net followed by unwashed Olyset Plus; however, the 95 \% CIs for the odds ratio indicated no significant difference among the five treatments (Table 2).

\section{Mortality}

Immediate mortality rate was nil with the control net during the entire evaluation period while with the treatments it ranged from 14.6 to $40.6 \%$, the highest killing was with unwashed Olyset Plus. Similarly, total mortality rate was significantly higher with all treatments (96.3-100.0 \%) than the untreated net (2\%) (Table 1). Results of logistic regression analysis (arms with $100 \%$ total mortality were not included in the analysis: unwashed Olyset Net, conventionally treated polyester net, unwashed Olyset Plus) showed that the mortality was significantly higher with Olyset Net washed 20 times (OR and $95 \%$ CI: 1287.0 and 252.9-6550.3) and Olyset Plus washed 20 times (1732.5 and 202.7-14,810.7) compared to untreated polyester net (Table 2). However, Olyset Net and Olyset Plus after washing 20 times did not differ significantly (95\% CI for the odd ratios overlap), indicating their similar killing effect.

\section{Residual activity of the insecticide on the nets}

Prior to any wash, all treatments caused $100 \%$ mortality of An. stephensi while mortality was nil with the untreated net. After 20 washes, mortality with Olyset Net and Olyset Plus was $62 \%$ and $90 \%$, respectively. Prior to use in the experimental huts, mortality of An. fluviatilis was $100 \%$ with all LLIN treatments and $86.0 \%$ with the conventionally treated net; only $2.0 \%$ mortality with the untreated net. After the hut evaluation, mortality was $100 \%$ with all LLIN treatments and $96.0 \%$ with the conventionally treated net; mortality was $4 \%$ with untreated net (Table 3 ).

\section{Insecticide content}

Prior to washing, the permethrin content in two samples of unwashed Olyset Net (19.9 and $20.0 \mathrm{~g} / \mathrm{kg}$ ) and Olyset

Table 3 Results of cone-bioassays

\begin{tabular}{|c|c|c|c|c|c|c|c|c|c|}
\hline \multirow[t]{2}{*}{ SI no } & \multirow[t]{2}{*}{ Arms } & \multicolumn{2}{|c|}{ Before any wash } & \multicolumn{2}{|c|}{ After 20 washes } & \multicolumn{2}{|c|}{$\begin{array}{l}\text { Prior to hut evalu- } \\
\text { ation }\end{array}$} & \multicolumn{2}{|c|}{$\begin{array}{l}\text { After hut evalu- } \\
\text { ation }\end{array}$} \\
\hline & & NE & CM (\%) & NE & CM (\%) & NE & CM (\%) & NE & CM (\%) \\
\hline 1 & Untreated polyester net & 50 & 0 & 50 & 0 & 50 & 2 & 50 & 4 \\
\hline 2 & Unwashed Olyset Net & 50 & 100 & - & - & 50 & 100 & 50 & 100 \\
\hline 3 & $\begin{array}{l}\text { Polyester net conventionally treated, washed } \\
\text { until just before exhaustion }\end{array}$ & 50 & 100 & 50 & $82^{\mathrm{a}}$ (4 washes) & 50 & 86 & 50 & 96 \\
\hline 4 & Olyset Net washed 20 times & 50 & 100 & 50 & 62 & 50 & 100 & 50 & 100 \\
\hline 5 & Olyset Plus LLIN washed 20 times & 50 & 100 & 50 & 90 & 50 & 100 & 50 & 100 \\
\hline 6 & Unwashed Olyset Plus LLIN & 50 & 100 & - & - & 50 & 100 & 50 & 100 \\
\hline
\end{tabular}

An. stephensi was used for cone-bioassays before any wash and after washes, whereas prior to hut evaluation and after hut evaluation, An. fluviatilis was used for the cone-bioassays

NE number of mosquitoes exposed, CM corrected mortality

a Washed until just before exhaustion 
Plus (19.1 and $18.8 \mathrm{~g} / \mathrm{kg}$ ) complied with the target dose of $20 \mathrm{~g} / \mathrm{kg}( \pm 3 \mathrm{~g} / \mathrm{kg})$ and $20 \mathrm{~g} / \mathrm{kg}( \pm 25 \%)$, respectively. In Olyset Net and Olyset Plus washed 20 times, the permethrin content was 17.7 and $14.1 \mathrm{~g} / \mathrm{kg}$, respectively, corresponding to an overall active ingredient retention of 88 and $75 \%$, respectively. The PBO content in two samples of unwashed Olyset Plus (9.0 and $8.8 \mathrm{~g} / \mathrm{kg}$ ) complied with the target dose of $10 \mathrm{~g} / \mathrm{kg}( \pm 25 \%)$. The PBO content was $3.96 \mathrm{~g} / \mathrm{kg}$ after 20 washes, corresponding to an overall PBO retention of $45 \%$ (Table 4 ).

The unwashed CTN contained $509.4 \mathrm{mg} / \mathrm{m}^{2}$ (15.3 g/ $\mathrm{kg}$ ) permethrin and after washing to just before exhaustion the permethrin content was $370.3 \mathrm{mg} / \mathrm{m}^{2}(11.4 \mathrm{~g} /$ $\mathrm{kg}$ ), corresponding to a retention rate of $74 \%$. After the experimental hut evaluation, the permethrin and/or PBO content in the tested Olyset Net and Olyset Plus did not decrease significantly.

\section{Discussion}

The first LLIN to receive full recommendation of the WHOPES [20] was Olyset Net; since then, more brands of nets have been granted either interim or full recommendation. However, all the nets including Olyset Net are produced using a single class of insecticide,

\section{Table 4 Results of chemical analysis}

\begin{tabular}{|c|c|c|c|c|}
\hline Treatment & $\begin{array}{l}\text { Before } \\
\text { washing }\end{array}$ & $\begin{array}{l}\text { After } \\
\text { washing }\end{array}$ & $\begin{array}{l}\text { Al retention } \\
\text { (\% of wash } 0 \text { ) }\end{array}$ & $\begin{array}{l}\text { After } \\
\text { testing }\end{array}$ \\
\hline \multicolumn{5}{|l|}{ Permethrin content (g/kg) } \\
\hline Unwashed Olyset Net & 19.94 & - & - & 19.34 \\
\hline $\begin{array}{l}\text { Olyset Net washed } 20 \\
\text { times }\end{array}$ & 20.01 & 17.68 & $88 \%$ & 17.58 \\
\hline $\begin{array}{l}\text { Unwashed Olyset Plus } \\
\text { LLIN }\end{array}$ & 19.13 & - & - & 17.64 \\
\hline $\begin{array}{l}\text { Olyset Plus LLIN washed } \\
20 \text { times }\end{array}$ & 18.82 & 14.11 & $75 \%$ & 13.75 \\
\hline $\begin{array}{l}\text { Polyester net con- } \\
\text { ventionally treated, } \\
\text { washed until just } \\
\text { before exhaustion }\end{array}$ & 15.33 & 11.36 & $74 \%$ & 10.42 \\
\hline Untreated polyester net & $<1$ & $<1$ & - & $<1$ \\
\hline \multicolumn{5}{|c|}{ Piperonyl butoxide content (g/kg) } \\
\hline Unwashed Olyset Net & $<1$ & $<1$ & - & $<1$ \\
\hline $\begin{array}{l}\text { Olyset Net washed } 20 \\
\text { times }\end{array}$ & $<1$ & $<1$ & - & $<1$ \\
\hline $\begin{array}{l}\text { Unwashed Olyset Plus } \\
\text { LLIN }\end{array}$ & 9.02 & - & - & 8.26 \\
\hline $\begin{array}{l}\text { Olyset Plus LLIN washed } \\
20 \text { times }\end{array}$ & 8.79 & 3.96 & $45 \%$ & 3.84 \\
\hline $\begin{array}{l}\text { Polyester net con- } \\
\text { ventionally treated, } \\
\text { washed until just } \\
\text { before exhaustion }\end{array}$ & $<1$ & $<1$ & - & $<1$ \\
\hline Untreated polyester net & $<1$ & $<1$ & - & $<1$ \\
\hline
\end{tabular}

pyrethroids, because of their promising activity against mosquitoes and low mammalian toxicity.

In view of vectors developing resistance to pyrethroids, manufacturers produce new vector control tools/products including mixtures of insecticides comprising at least two active ingredients having dissimilar mode of action as part of resistance management strategy. Olyset Plus was the first LLIN to incorporate PBO, a synergist, into its every fibre and all surfaces, facilitating enhanced knock down and kill against pyrethroid-resistant mosquitoes. $\mathrm{PBO}$ has long been used to improve the performance of pyrethroid insecticides especially household aerosols [21]. Synergists are chemicals that do not possess insecticidal activity of their own but enhance the insecticidal performance of other chemicals.

Insects, in general, despite their susceptible or resistance status, contain enzymes for metabolizing xenobiotic compounds (insecticides) and converting them to a non-toxic ones that are finally removed through excretion. Cytochrome P450s are one such oxidising enzymes that detoxify pyrethroids before the preferred effect is attained. In resistant insects the activity of these enzymes can greatly be enhanced which can significantly reduce the efficacy of an insecticide. PBO is a potent inhibitor of these enzymes blocking/nullifying their action thereby inhibiting the breakdown or the metabolism of insecticides, rendering the insecticide more effective. PBO also increases the activity of pyrethroids in susceptible insects, so adding PBO to a LLIN has a benefit even in areas where there is no resistance. Many studies demonstrated the impact of $\mathrm{PBO}$ on pyrethroid resistance; the net incorporating permethrin and $\mathrm{PBO}$ showed significantly better performance in terms of insecticidal activity against multiple resistant (to permethrin) populations of An. gambiae than the net treated only with permethrin $[9,22]$.

The current experimental hut evaluation of Olyset Plus was conducted in an area where An. fluviatilis was the primary vector of malaria and susceptible to pyrethroids [5]. Prior to any wash, all treatments, including the two LLIN treatments (Olyset Plus and Olyset Net), caused $100 \%$ mortality of An. stephensi. After 20 washes, the mortality rates induced by the LLIN treatments declined, much with Olyset Net (100-62 \%) than with Olyset Plus (100-90 \%). However, the insecticidal effect of the LLIN treatments regained subsequently to cause $100 \%$ mortality of An. fluviatilis prior to and after the hut evaluation. The reduced mortality after washing could also be due to the difference in physiological response of the two vector species to the pyrethroid though they were phenotypically susceptible to the insecticide. With the conventionally treated net $(\mathrm{CTN})$ also, after washing four times (number of washes required before exhaustion) mortality of $A n$. stephensi declined from 100-82 \%; however, prior to and 
after the hut trial, mortality of An. fluviatilis induced by the CTN was on higher side, 86 and $96 \%$, respectively.

Relatively higher efficacy of Olyset Plus (both washed and unwashed) in terms of deterrence (preventing mosquito entry) was confirmed compared to the standard Olyset Net and the untreated control. But, the same LLIN treatment, when tested against the moderate pyrethroid resistant An. gambiae, there was no significant reduction in the entry rates (deterrence) [9]. The unwashed Olyset Plus conferred a higher inhibition of blood feeding than Olyset Net, but after 20 washes the inhibition effect was almost equivalent to washed and unwashed Olyset Net. The induced exophily was significantly lower with unwashed Olyset Plus compared to Olyset Net as observed for An. gambiae in Benin during an experimental hut study [9]. But, interestingly, after 20 washes, Olyset Plus induced higher exophily than Olyset Net. Another combination LLIN, PermaNet 3.0, has also been reported to induce more exophily after 20 washes [16]. In terms of insecticidal activity (killing effect), all treatments were comparable, but caused significantly high mortality compared to the control.

The decline in permethrin content in Olyset Plus $(18.8-14.1 \mathrm{~g} / \mathrm{kg})$ with $75 \%$ retention after 20 washes indicated depletion of bio-availability of AI on the net surface by the washes. In the case of Olyset Net, the depletion, after 20 washes, was relatively lower $(20.0-17.7 \mathrm{~g} / \mathrm{kg})$ as the $\mathrm{AI}$ retention was $88 \%$. In contrast, Gimnig et al. [23] reported no significant decrease of permethrin content in Olyset Net after washing as its biological activity could be restored by heat-assisted regeneration. In the current study, although there was a reduction in permethrin content of Olyset Plus after washing, it was not reflected from its performance against the susceptible vector species in the experimental hut, as it produced comparable effect. The AI retention rate of $\mathrm{PBO}$ in Olyset Plus was $45 \%$ after 20 washes.

\section{Conclusion}

The evaluation in experimental huts demonstrated that the performance of Olyset Plus washed 20 times was equal to the conventionally treated net and Olyset Net in terms of deterrence, induced exophily, blood-feeding inhibition and killing effect against the malaria vector species and thereby fulfilled the WHO efficacy criteria of Phase II evaluation for LLIN. However, the benefit of incorporating $\mathrm{PBO}$ and permethrin together in a longlasting treatment could not be demonstrated in the current study as the target vector species was fully susceptible to pyrethroids. In India, among the six ( $A n$. culicifacies, An. stephensi, An. fluviatilis, Anopheles minimus, Anopheles baimaii and Anopheles sundaicus) primary vectors of malaria, An. culicifacies, which is a rural and peri-urban vector contributing to around $65 \%$ of the malaria cases [24], has developed wide-spread resistance to DDT and malathion and recently to synthetic pyrethroids in many states [25-28]. Except An. stephensi, which has also developed wide-spread resistance to DDT and malathion, the other vector species are susceptible to all the insecticides. Olyset Plus, with its intrinsic bio-efficacy could be an effective vector control tool to prevent transmission of malaria by susceptible vectors like $A n$. fluviatilis in India. With the potential benefit of incorporating a synergist [9], it could also be considered for use in areas of the pyrethroid resistant vector, An. culicifacies. However, before any community level testing is done, this net should be tested at hut scale against An. culicifacies. Further, although pyrethroid resistance is a problem with only An. culicifacies in India, considering the quantum of malaria it transmits, it would be essential to promote use of PBO mixed pyrethroid nets for an effective control of malaria in rural areas.

\section{Abbreviations \\ PBO: piperonyl butoxide; LLINs: long-lasting insecticidal nets; WHO: World Health Organization; ITNs: insecticide-treated nets; IRS: indoor residual spray; WHOPES: World Health Organization Pesticide Evaluation Scheme; MSL: mean sea level; API: annual parasite incidence; CTN: conventionally treated net; OR: odds ratio; Cl: confidence interval; IRR: incidence rate ratio; BFI: blood feeding inhibition.}

\section{Authors' contributions}

KG, SSS and TV designed and performed the study. SS compiled and analyzed the data. OP carried out chemical analysis. KG and SSS drafted the manuscript. RSY and PJ critically reviewed and revised the manuscript. All authors contributed to the writing of the manuscript and approved the final version. All authors read and approved the final manuscript.

\section{Author details}

${ }^{1}$ Vector Control Research Centre (ICMR), Medical Complex, Indira Nagar, Puducherry 605 006, India. ${ }^{2}$ World Health Organization Pesticide Evaluation Scheme, Department of Control of Neglected Tropical Diseases, WHO, Geneva, Switzerland. ${ }^{3}$ Agriculture and Natural Environment Department (D3), Walloon Agricultural Research Centre (CRA-W), Gembloux, Belgium.

\section{Acknowledgements}

The assistance rendered by the technical staff of VCRC Field Station, Koraput is gratefully acknowledged. We thank the WHOPES for providing the LLINs for evaluation and for the financial support to carry out the study.

\section{Competing interests}

The authors declare that they have no competing interests.

\section{Availability of data and materials}

Raw data in field sheets and computer-encoded data (MS work sheet) are available in the Centre's archive. The net materials used for the evaluation and the balance insecticide (permethrin) after the conventional treatment are sent back to the sponsor.

\section{Consent for publication}

Consent has been given by all co-authors for the publication.

\section{Ethics approval and consent to participate}

To involve human volunteers in the study, clearance was obtained from the Institute's Human Ethics Committee. Written consent for their participation was obtained from all the volunteers and each one was remunerated. 


\section{Funding}

Financial support for conducting the study was received from the WHO Pesticide Evaluation Scheme.

Received: 12 March 2016 Accepted: 4 July 2016

Published online: 21 July 2016

\section{References}

1. Ministry of Health and Family Welfare. Government of India. Directorate General of Health Services, National Vector Borne Disease Control Programme, New Delhi. Malaria situation in India 2015. http://nvbdcp.gov.in/ malaria-new.html.

2. Bhatia R, Rastogi RM, Ortega L. Malaria successes and challenges in Asia. J Vector Borne Dis. 2013;50:239-47.

3. Ministry of Health and Family Welfare. Government of India. Directorate General of Health Services, National Vector Borne Disease Control Programme, New Delhi. Strategic Plan for Malaria Control in India. A five-year strategic plan (2012-2017). http://www.nvbdcp.gov.in/Doc/StrategicAction-Plan-Malaria-2012-17-Co.pdf.

4. Enayati A, Hemingway J. Malaria management: past, present, and future. Annu Rev Entomol. 2010;55:569-91.

5. Gunasekaran K, Sahu SS, Vijayakumar T, Vaidyanathan K, Yadav RS, Pigeon $\mathrm{O}$, et al. Comparison of efficacy of five types of long-lasting insecticidal nets against Anopheles fluviatilis, the primary malaria vector in EastCentral India. J Med Entomol. 2014;51:785-94.

6. WHO. Pesticide Evaluation Scheme. Report of the tenth WHOPES Working Group Meeting. 2007; WHO/CDS/NTD/WHOPES/2007.1.

7. Banek K, Kilian A, Allan R. Evaluation of Interceptor long-lasting insecticidal nets in eight communities in Liberia. Malar J. 2010:9:84.

8. Tami A, Mubyazi G, Talbert A, Mshinda H, Duchon S, Lengeler C. Evaluation of Olyset ${ }^{\mathrm{TM}}$ insecticide-treated nets distributed seven years previously in Tanzania. Malar J. 2004;3:19.

9. Pennetier C, Bouraima A, Chandre F, Piameu M, Etang J, Rossignol M, et al. Efficacy of Olyset ${ }^{\circledR}$ Plus, a new long-lasting insecticidal net incorporating permethrin and piperonyl-butoxide against multi-resistant malaria vectors. PLOS ONE. 2013;8:e75134.

10. WHO. Pesticide Evaluation Scheme. Review of Bioßash GR, PermaNet 2.0, PermaNet 3.0, PermaNet 2.5 and Lambdacyhalothrin LLIN. Report of the XII WHOPES Working Group Meeting. 2008; WHO/HTM/NTD/ WHOPES/2009.1.

11. WHO. Pesticide Evaluation Scheme. Review of Olyset LLIN, Dawaplus 2.0 LLIN, Tianjin Yorkool LLIN. Report of the XIII WHOPES Working Group Meeting. 2009; WHO/HTM/NTD/WHOPES/2009.5

12. WHO. Review of Alphacypermethrin 250 WG-SB ICON Maxx Netprotect Ln Chlorfenapyr 240 SC. 2014; WHO/HTM/NTD/WHOPES/2014.3.
13. Rivero A, Vezilier J, Weill M, Read AF, Gandon S. Insecticide control of vector-borne diseases: when is insecticide resistance a problem? PLoS Pathog. 2010;5:e1001000.

14. Ranson H, N'Guessan R, Lines J, Moiroux N, Nkuni Z, Corbel V. Pyrethroid resistance in African anopheline mosquitoes: what are the implications for malaria control? Trends Parasitol. 2011;28:91-8.

15. WHO. Global plan for insecticide resistance management in malaria vectors (GPIRM). Geneva: World Health Organization; 2012

16. Corbel V, Chabi J, Dabire RK, Etang J, Nwane P, Pigeon O, et al. Field efficacy of a new mosaic long-lasting mosquito net (PermaNet 3.0) against pyrethroid-resistant malaria vectors: a multi-centre study in Western and Central Africa. Malar J. 2010;27:113.

17. N'Guessan R, Corbel V, Akogbeto M, Rowland M. Reduced efficacy of insecticide treated nets and indoor residual spraying for malaria control in pyrethroid resistance area, Benin. Emerg Infect Dis. 2007;13:199-206.

18. Asidi A, N'Guessan R, Akogbeto M, Curtis C, Rowland M. Loss of household protection from use of insecticide-treated nets against pyrethroidresistant mosquitoes, Benin. Emerg infect Dis. 2012;18:1101-6.

19. WHO. Guidelines for laboratory and field testing of long-lasting insecticidal mosquito nets. Geneva, World Health Organization, 2005; WHO/ CDS/WHOPES/GCDPP/2005.11.

20. WHO. Report of the 5th WHOPES Working Group meeting. Review of Olyset Net and bifenthrin 10\%WP, 30-31 October 2001 Geneva. WHO/ CDS/WHOPES/2001.4

21. Anonymous. 2014. Sumitomo Chemical, Vector Control Division, Leading innovation in vector control. http://www.sumivector.com.

22. Awolola TS, Oduola OA, Strode C, Koekemoer LL, Brooke B, Ranson H. Evidence of multiple pyrethroid resistance mechanisms in the malaria vector Anopheles gambiae sensu stricto from Nigeria. Trans R Soc Trop Med Hyg. 2009;103:1139-45.

23. Gimnig JE, Lindblade KA, Mount DL, Atieli FK, Crawford S, Wolkon A, et al. Laboratory wash resistance of long-lasting insecticidal nets. Trop Med Int Health. 2005:10:1022-9.

24. Sharma VP. Fighting malaria in India. Curr Sci. 1998;75:1127-40.

25. Raghavendra K, Barik TK, Sharma SK, Das MK, Dua VK, Pandey A, et al. A note on the insecticide susceptibility status of principal malaria vector Anopheles culicifacies in four states of India. J Vector Borne Dis. 2014:51:230-4

26. Mittal PK, Adak T, Singh OP, Raghavendra K, Subbarao SK. Reduced susceptibility to deltamethrin in Anopheles culicifacies sensu lato in District Ramanathapuram in Tamil Nadu: selection of a pyrethroid resistant strain. Curr Sci. 2002;82:185-8.

27. Singh RK, Kumar G, Mittal PK. Insecticide susceptibility status of malaria vectors in India. A review. Int J Mosq Res. 2014;1:5-9.

28. Sahu SS, Gunasekaran K, Vijayakumar T, Jambulingam P. Triple insecticide resistance in Anopheles culicifacies: a practical impediment for malaria control in Odisha State, India. Indian J Med Res. 2015;142:59-63.

\section{Submit your next manuscript to BioMed Central and we will help you at every step:}

- We accept pre-submission inquiries

- Our selector tool helps you to find the most relevant journal

- We provide round the clock customer support

- Convenient online submission

- Thorough peer review

- Inclusion in PubMed and all major indexing services

- Maximum visibility for your research

Submit your manuscript at www.biomedcentral com/submit
C Biomed Central 